\title{
Molecular detection, prevalence and risk factors of Theileria orientalis infection among cattle in Peninsular Malaysia
}

\begin{abstract}
There is need to confirm the presence of Theileria orientalis among the cattle population in Peninsular Malaysia and to evaluate the risk factors associated with the infection. To this effect, blood samples were collected from 1045 cattle from 43 farms throughout the entire States of Peninsular Malaysia. The collected blood samples were subjected to DNA extraction and subsequent PCR amplification of the major piroplasm surface protein (MPSP) gene of the haemoprotozoan. Representative positive amplicons were purified, sequenced and compared with other sequences of the MPSP gene of T. orientalis curated from the GenBank. A wellstructured questionnaire was used to get information about each cattle, it's demography, the bio-security, environmental and management factors. Univariate and multivariate analysis were used for the statistical evaluation, with significance set at $p<0.05$. A total prevalence of 49.76\% (520/1045; 95\% CI: 46.73 - 52.79) was obtained. Types of breeds, age, production type, herd size, level of farm biosecurity, farm size, presence of other animal species in the farm, management systems and prophylaxis were significantly $(\mathrm{p}<0.05)$ associated with the prevalence of T. orientalis. This study confirmed the presence of T. orientalis and establish that the haemoprotozoan is endemic among cattle in Peninsular Malaysia.
\end{abstract}

